\title{
Influence of Fair Value on the Qualitative Characteristics and Decision Usefulness of Accounting Information
}

\author{
Sin-Hui Yen ${ }^{1}$, Yun-Ting Lai ${ }^{2} \&$ Hui-Ling Chen $^{3}$ \\ ${ }^{1}$ Department of Accounting, Tamkang University, New Taipei City, Taiwan \\ ${ }^{2}$ Department of Management Sciences, Tamkang University, New Taipei City, Taiwan \\ ${ }^{3}$ Department of Accounting, Shih Chien University, Taipei City, Taiwan \\ Correspondence: Yun-Ting Lai, Department of Management Sciences, No.151, Yingzhuan Rd., Tamsui Dist., \\ Tamkang University, New Taipei City 25137, Taiwan (R.O.C.).Tel: 011-886-929-770-107.
}

Received: October 14, 2016

Accepted: November 6, 2016

Online Published: November 9, 2016

doi:10.5430/afr.v5n4p179

URL: http://dx.doi.org/10.5430/afr.v5n4p179

\begin{abstract}
Expanding the application of fair value is a key initiative of the International Financial Reporting Standards. Previous standards have interpreted the concept of fair value (e.g., IFRS 13, IFRS 9); however, the application of fair value-related measures remains largely up to the discretion and professional judgment of individual accountants. The conceptual frameworks proposed by the International Accounting Standards Board and Financial Accounting Standards Board specifically outline the relationships among the qualitative characteristics of accounting information. In this study, we explore the issue of fair value in a variety of situations to identify potential relationships among relevance, representational faithfulness and decision usefulness. We also investigate whether relevance and representational faithfulness are mutually inclusive or exclusive. Our objective is to elucidate the relationship between fair value information and user decisions. We obtain responses from 257 students enrolled in Master's-level accounting department programs at eight Taiwanese universities to determine the fair value of available-for-sale financial instruments. We adopt a $2 \times 2$ mixed design in conjunction with ANOVA and SEM to analyze the relationships among the qualitative characteristics of accounting information. Our findings demonstrate that representational faithfulness influences assessments pertaining to representational faithfulness, relevance, and decision usefulness, whereas relevance influences only assessments pertaining to relevance and decision usefulness. Additionally, representational faithfulness and relevance both are significantly correlated with the usefulness of decisions. The results are particularly meaningful because the method use to evaluate fair value indeed influences how the users of financial statements perceive the qualitative characteristics of fair value information (relevance and representational faithfulness).
\end{abstract}

Keywords: Fair value, Relevance, Representational faithfulness, Useful decision

\section{Introduction}

Since 2013, listed and OTC companies in Taiwan have adopted the International Financial Reporting Standards (IFRS) issued by the International Accounting Standards Board (IASB) for the preparation of financial statements. IFRSs place considerable emphasis on fair value. Unfortunately, none of the various versions of the IFRS (e.g., IFRS 13 and IFRS 9) explains in detail the concepts associated with fair value and thus the application of fair value in accounting and auditing practices is still based on the discretion and professional judgment of individuals. The means by which fair value influences the judgments and decisions of those reading financial statements is a crucial issue warranting further investigation. In view of this, this study explores the degree to which the qualitative characteristics of accounting information influence investors. Our objective is to elucidate the relationship between reports on fair value and user decisions. In particular, we investigate the influence of asset-holding intention (short-term or long-term) and the determination of fair value by using various appraisal methods (e.g., market-based or model-based) as well as the relevance, representational faithfulness (previously referred to as reliability), and usefulness of information on fair value.

In the past, emphasis was placed on the representational faithfulness of financial statements, and as a result, historical costs were the most common basis for measurement. Historical costs contain traces of records of past transactions and information with a high degree of representational faithfulness; however, the relevance of this 
information in decision making is often questioned. To enhance the practical value and relevance of financial statements, current IFRS encourage the idea of fair value in many elements of financial reporting (including financial and non-financial instruments). But, its influence on representational faithfulness has yet to be elucidated because the determination of fair value involves manifold factors such as professional appraisal skills, the subjective judgment of the appraiser, the appraisal model (including parameters), and fluctuations in financial markets. All of these factors can directly influence the representational faithfulness of fair value. Moreover, entities may decide by themselves how to determine fair value, leading users of financial statements to have to evaluate the representational faithfulness of information on fair value from a variety of sources. This has led to considerable debate concerning the means of striking a balance between relevance and representational faithfulness in fair value accounting.

To enhance the consistency and comparability of fair value measurements and disclosures, IFRS 13 developed a three-level fair value hierarchy. Each level has its own priorities, implying that the degree of representational faithfulness at Level 1 is higher than that at Levels 2 and 3. For example, Song, Thomas, and He (2010) found that the value relevance of Level 1 and Level 2 fair values is greater than that of Level 3 fair values based on an analysis of the quarterly reports of banking firms in 2008. Kadous, Koonce, and Thayer (2012) indicated that the method (market value or appraisal model measurements) used by managers to appraise real estate influences how investors judge the representational faithfulness of fair value. This is a clear illustration that the means by which fair value is determined may impact how information users judge the representational faithfulness of fair value, which in turn influences their decisions. In this study, we therefore manipulate the level of fair values (market-based and model-appraised) to clarify the relationship between fair value level and the assessment of representational faithfulness.

Koonce, Nelson, and Shakespeare (2011) posited that the relevance of the fair value information of financial instruments perceived by users is influenced by various factors. For instance, they found that investors observe a greater degree of relevance in the fair value of financial assets managed by individuals with an intention to sell immediately than in those of financial assets meant to be held until the expiration date. Hague and Willis (1999) and Kadous et al. (2012) also discovered that the intention of the asset manager to hold assets influences the way in which decision makers perceive the relevance of fair value information. This finding demonstrates the importance of asset-holding intention in determining whether investors consider fair value information to be relevant. In this study, we thus manipulate the asset-holding intention of the appraised subjects (short-term or long-term) to measure the relevance of fair value information.

The Conceptual Framework for Financial Reporting issued by the IASB in 2011 states that useful financial information should have two basic qualitative characteristics: relevance and representational faithfulness. The first objective of this study is thus to explore how information users determine the degree of relevance, representational faithfulness, and decision usefulness of fair value information under various conditions (different fair value appraisal methods and asset-holding intention). The Conceptual Framework of the IASB also implies that relevance and representational faithfulness are the two independent qualitative characteristics that a piece of information must have to be useful in decision making (Maines \& Wahlen, 2006). However, some studies have reported a correlation between relevance and representational faithfulness, which casts doubt on such a statement. Kadous et al. (2012), for example, discovered that representational faithfulness has a unidirectional influence on relevance and that the representational faithfulness of fair value information can directly affect its usefulness in decision making as well as indirectly influencing decision usefulness via relevance. The relationships among these qualitative characteristics of information and the order in which they should be used can thus facilitate the formulation of a conceptual framework as a guide for future standards. Thus, the second objective of this study is to elucidate the relationship between decision usefulness and the qualitative characteristics of fair value information (relevance and representational faithfulness).

By using an experimental approach, we manipulate the method of appraising (market-based and model-appraised) fair value information of available-for-sale financial assets and the asset-holding intention of corporations (short-term or long-term). The primary aim is to determine how the users of financial statements judge the relevance and representational faithfulness of fair value information under various circumstances. We also seek to determine whether relevance and representational faithfulness are mutually independent.

Participants in this experiment comprise 257 graduate students from accounting departments in eight universities in Taiwan. Our results indicate that the method used to appraise fair value indeed influences the degree to which decision makers perceive representational faithfulness and that market-based appraisals instill a greater sense of confidence in the fidelity of the information. Further, the asset-holding intention of corporations largely determines 
the perceptions of decision makers with regard to the relevance of fair value information. We also find that the degree of relevance and representational faithfulness perceived by participants influences the decision usefulness of the information. Furthermore, we determine that relevance and representational faithfulness are correlated (i.e., they are not mutually independent).

The primary contributions of this study are as follows. First, our findings help clarify how the method of determining fair value influences representational faithfulness, which is particularly important for corporations. Next, this study demonstrates that the intentions of a corporation with regard to holding financial assets influence how decision makers regard the relevance of information. However, as professional knowledge influences professional judgment, so do information-processing procedures such as the cognitive interpretation of financial information. Thus, we offer a first step to understanding how decision makers assess the qualitative characteristics of accounting information, as proposed by the Conceptual Framework.

The remainder of this paper is outlined as follows. Section 2 presents a review of the relevant literature used in the construction of the hypotheses in this study. Section 3 defines the variables used in the experiment. Section 4 presents the findings of this study, and Section 5 presents the conclusions and limitations of this study as well as suggestions for future research.

\section{Literature Review and Study Hypotheses}

\subsection{Fair Values under IFRS 13}

The trade-off between the relevance and representational faithfulness of fair value information has long been debated among academics (Landsman, 2007; Penman, 2007; Hitz, 2007; Bricker \& Chandar, 2012; Barth, 1994; Barth, Landsman, \& Wahlen, 1995; Barth, Beaver, \& Landsman, 1996). Supporters of the fair value method maintain that fair value information is of greater relevance than historical costs as it provides a more accurate reflection of fluctuations in actual prices. Other researchers have argued that fair value information is easily susceptible to manipulation by managers or estimation error, which means that it cannot be directly verified by investors. These issues create information asymmetry between investors and managers, thereby calling into question the representational faithfulness of fair values (Landsman, 2007; Penman, 2007). In a review of the literature associated with fair value, Landsman (2007) discovered that most researchers consider fair values (recognized or disclosed) to be useful in investor decisions. However, other studies have found that the degree of usefulness is affected by the number and source of errors in fair value measurement, such as the internal management or external appraisal of corporations (Cotter \& Richardson, 2002), and that fair value is obtained from the final price in an active market (Song et al., 2010).

\subsection{Variables Influencing the Relevance and Representational Faithfulness of Fair Value Information}

Relevance generally indicates the form of the information, whereas representational faithfulness refers to the way in which the information is measured. We believe that some of the noteworthy issues associated with fair value may be associated with the quality of the information used for evaluation. First, fair values can be measured through the direct observation of markets or an estimation process. In this manner, the method used for fair value appraisal (market-based or model-appraised) may influence how investors perceive information with regard to its representational faithfulness and usefulness in making decisions. Furthermore, despite the fact that fair values bring financial statement elements closer to actual prices and provide timely information for use in decision making, the intentions of the corporation with regard to holding assets (short- or long-term) may also impact the relevance of fair values. Below, we examine in greater detail each of the factors associated with the qualitative characteristics of fair value.

\subsubsection{Relationship Between Asset-holding Intention and Relevance}

The majority of previous investigations into fair value in financial statements have used archival methods with a focus on the value relevance of fair value information (Barth, 1994; Barth et al., 1996; Eccher, Ramesh, \& Thiagarajan, 1996; Nelson, 1996; Carroll, Linsmeier, \& Petroni, 2003; Barth, Landsman, \& Lang, 2008; Song et al., 2010). However, none of these studies shows a direct relationship between the value relevance of fair value and the qualitative characteristics of accounting information.

Hague and Willis (1999) further claimed that the relevance of fair value is directly associated with the asset-holding intention regarding the financial instrument. This assertion was supported by Koonce et al. (2011), who found that the fair value of financial assets that are soon to be sold are of greater relevance than are those held until the expiration date. By using real estate as the experimental sample, Kadous et al. (2012) also discovered that fair value in investment properties intended for sale at a later date have greater relevance to decision making than do those of 
owner-occupied properties.

In summary, previous researchers have found that the intention behind holding assets is a crucial factor in determining the relevance of fair value information. Thus, in this study, we manipulate asset-holding intention to gauge the relevance of fair value information. Accordingly, we propose the following hypothesis:

H1: Decision makers believe that the fair value of financial assets intended for sale after a short period of time is of greater relevance than that of assets held for longer periods.

\subsubsection{Relationship between the Methods Used in the Appraisal of Fair Value and Representational Faithfulness}

Representational faithfulness is a crucial qualitative characteristic of accounting information; however, it can be difficult to conceptualize and therefore to define with regard to accounting standards. Maines and Wahlen (2006) observed that users base their assessment of the representational faithfulness of information according to the procedure by which the corporation determines and processes accounting data. Unreliable appraisal methods, a lack of discretion on the part of managers, and the direct manipulation of data can all affect estimates of fair value. For users of financial statements, only reports deemed both relevant and representational faithful are of any practical use in making decisions.

Petroni and Wahlen (1995) discovered that the fair value of equity securities and treasury shares is of greater relevance than that of corporate bonds. They then inferred that the prices of securities on active markets are of greater relevance than are those on inactive markets. In other words, when a financial commodity does not have an active market (lower representational faithfulness), then its fair value is of little relevance (Nelson, 1996). Cotter and Richardson (2002) investigated the means by which the source of fair value information influences its usefulness in Australian companies. They found that when an independent third party (rather than an internal board of directors) reassesses the value of factory buildings and equipment, investors are more likely to treat the findings as reliable. In a similar study, Muller and Riedl (2002) observed that market participants treat fair values obtained through external evaluation as more representational faithful.

As shown above, the method by which fair value is appraised (market-based or model-appraised) influences the degree to which users perceive the information they receive as representational faithful. Thus, we manipulate the level of fair values to gauge the representational faithfulness of fair value information. This leads us to the following hypothesis:

H2: Decision makers believe that the fair value of financial assets determined using directly observable markets is of greater relevance than fair values obtained through in-house appraisals using evaluation models.

\subsection{Quality of Accounting Information and Its Usefulness in Decision Making}

\subsubsection{Relationships among Relevance, Representational Faithfulness, and Usefulness in Guiding Decisions}

For users of financial statements, only reports deemed both relevant and representational faithful are of any practical use in making decisions. Duncan and Moores (1988) asserted that fair value information is more useful than historical cost accounting because it has greater relevance and representational faithfulness. Studies have also shown that fair value information on financial products provides greater explanatory power for the stock prices of finance and insurance companies, which is an indication that the fair values of financial products possess value relevance (Barth, 1994; Barth et al., 1996; Nelson, 1996; Barth and Clinch, 1998; Carroll et al., 2003; Bricker \& Chandar, 2012).

Many previous studies have reported that fair value information is relevant to decision making, which means that the same information could be useful in the evaluation of stocks. However, the fact that these studies examined the joint influence of relevance and representational faithfulness on decisions (Barth, Beaver, and Landsman, 2001) gives no indication of how the relevance or representational faithfulness of fair value estimates affects the usefulness of the information with regard to decision making. The Conceptual Framework explains that users of financial statements assess the relevance and representational faithfulness of information to judge its decision usefulness. This would imply that the two are mutually independent. Based on the Conceptual Framework and the findings of previous studies, we thus propose the following hypotheses:

H3A: Decision makers believe that fair value information on financial instruments with greater representational faithfulness is of greater usefulness in making decisions.

H3B: Decision makers believe that fair value information on financial instruments with greater relevance is of greater usefulness in making decisions. 


\subsubsection{Relationship between Relevance and Representational Faithfulness}

The Conceptual Framework clearly specifies that the most efficient and effective procedure involves the identification of relevant information before considering its representational faithfulness. This is grounded on the assertion consistently made by the IASB that relevance and representational faithfulness are two mutually exclusive qualitative characteristics. However, users of financial statements do not necessarily consider relevance and representational faithfulness to be mutually exclusive (Schipper, 2003; Dye \& Sridhar, 2004; Duncan \& Moores, 1988; Kadous et al., 2012). Indeed, Bricker and Chandar (2012) explored the usefulness of fair value and historical cost information with regard to decision making. They found that in both restricted and unrestricted financial assets, fair value information on financial assets provides greater explanatory power for stock prices than does historical cost information. In other words, decision makers perceive fair value information as highly relevant. They also found that unrestricted securities have greater explanatory power for stock prices than does historical cost information, which means that fair value information with greater representational faithfulness has greater relevance. This is an indication that the degree of representational faithfulness in the fair value information of financial assets may indeed influence the degree to which users of financial statements perceive it as relevant.

Kadous et al. (2012) observed that fair value information from a trusted source is seen as highly representational faithful, regardless of whether the real estate would be sold in the near future (high relevance) or in the distant future (low relevance). They also demonstrated that the representational faithfulness of fair value information influences users of financial statements with regard to their assessments of relevance. This means that relevance and representational faithfulness are not mutually exclusive, thereby supporting the expectations of attribute substitution theory.

Based on the above results, predict that when evaluating the relevance of fair value information, users of financial statements are more easily influenced by representational faithfulness because judging the relevance of fair value information can be difficult. Based on the theory of attribute substitution, people generally determine whether information comes from a reliable source before considering whether it is relevant to the decision setting. Therefore, if user estimates of representational faithfulness significantly influence their perceptions of relevance, we can assume that representational faithfulness directly influences the usefulness of information in decision making as well as indirectly influences its usefulness via relevance. Thus, we formulate the following hypothesis:

H4A: In the evaluation of fair value information, the estimates made by decision makers with regard to representational faithfulness influences their estimates of relevance, which in turn influences the degree to which the information is regarded as useful in guiding their decisions.

Most previous researchers have found that the representational faithfulness of accounting information influences the perceptions of financial statement users with regard to the relevance of information. Nevertheless, Barth et al. (2001) reported that when accounting information has value relevance, it means that the information is both relevant and faithfully represented. By contrast, if accounting information does not have value relevance, it is difficult to determine whether the reason is a lack of relevance or a lack of representational faithfulness. Thus, for users of financial statements, a certain degree of correlation is likely to exist between relevance and representational faithfulness. We therefore investigate the influence of relevance on representational faithfulness in accounting information and formulate the following hypothesis:

H4B: The degree to which decision makers perceive relevance in fair value information is associated with the degree to which they perceive representational faithfulness, which in turn determines how useful the information is in making decisions.

The relationship between the research model and hypotheses in this study, we illustrate in the Figure 1. (show the results section.)

\section{Methodology}

\subsection{Experimental Design}

We adopted a $2 \times 2$ mixed design to test our hypotheses. The independent variables included 1) the method used to obtain fair values (with two levels: market-based and model-appraised) and the asset-holding intentions of owners (with two levels: short-term and long-term). To determine whether the manipulation method influences the research findings and examine the robustness of the study results, we created four versions of the questionnaire with a between-subjects design or a within-subjects design for the two independent variables. Table 1 illustrates the manipulations applied to the independent variables. In versions 1 and 2, we adopted the between-subjects design to measure fair value and the within-subjects design for asset-holding intention. This resulted in the presentation of 
scenarios in which fair value was based on an active market or model appraisal. Nonetheless, we also present information for short-term and long-term holding to reveal whether respondents varied their responses in the face of different pieces of information (Panel A of Table 1). In versions 3 and 4, we adopted the within-subjects design to measure fair value and the between-subjects design for asset-holding intention (Panel B of Table 1).

Table 1. Variables and groups



Panel B: Within-subjects design for the method used to measure fair value and between-subjects design for asset-holding intention

\begin{tabular}{lllll}
\hline \multirow{2}{*}{ Short-term } & Based on an active market & 1 & \multirow{2}{*}{3} \\
\cline { 2 - 3 } & Estimated using the appraisal model & 2 & \\
\hline \multirow{2}{*}{ Long-term } & Based on an active market & 1 & \multirow{2}{*}{4} \\
\cline { 2 - 3 } & Estimated using the appraisal model & 2 & \\
\hline
\end{tabular}

\subsection{Case Scenarios}

In this study, we focused on appraising the value of an available-for-sale financial asset, which would be familiar to graduate students in accounting and of considerable practical importance. We designed the case scenarios in a manner that would allow participants to judge the qualitative characteristics and decision usefulness of the fair value information. A counterbalanced design was used to present two scenarios involving decisions related to accounting to control for potential order effects. Half of participants were first presented Scenario 1 in the experiment tool, whereas the other half were first presented Scenario 2.

\section{Background information:}

Company A invests NTD 100 million of idle funds in a common stock of Company B early one year and marks this investment as an available-for-sale financial asset. At the end of the year, the fair value of the stock has decreased to NTD 80 million, which means a loss of NTD 20 million (a decrease of 20\%, listed as an unrealized holding loss in the financial report). According to accounting standards, Company A would report on the balance sheet a fair value of NTD 80 million for the available-for-sale financial asset and list the unrealized holding loss of NTD 20 million under other income items (this would reduce the current equity of shareholders but would not affect earnings per share for the current period).

Please answer the following questions related to the following two scenarios based on the background information:

\section{Scenario 1:}

(1) Company B is a listed company and the fair value of the common stock (NTD 80 million) is based on an active securities market. Also:

(2) Owing to a need for funds, Company A plans to sell the investment at an opportune time in the following year, which means that Company A would categorize this available-for-sale financial asset as a current asset.

\section{Scenario 2:}

(1) Company B is a listed company and the fair value of the common stock (NTD 80 million) is based on an active securities market. Also:

(2) Company A is optimistic about the dividend-paying ability of Company B in the long-term and therefore intends to hold onto the stock for the next several years, which means that Company A would categorize this available-for-sale financial asset as a non-current asset. 
To familiarize participants with the meaning of the qualitative characteristics and respective standards, we had them respond to a few questions on a decision commonly encountered in everyday life: "Suppose you have an outdoor activity planned today, but it is cloudy outside. You already have a lot of things to carry, so you must decide whether to bring an umbrella. This decision is based on the weather forecast, which indicates that there is a $50 \%$ chance of rain." Participants were asked to describe the relevance, representational faithfulness, and decision usefulness of the information "a 50\% chance of rain" on an 11-point scale from 0 to 10, with 10 indicating the highest degree of each.

\subsection{Definitions of the Variables}

\section{Independent Variable 1 (fair value appraisal):}

(a) Market-based: The fair value of the common stock at the end of the year is based on an active securities market.

(b) Model-appraised: The fair value of the common stock at the end of the year is based on unobservable inputs calculated by using an investment model.

\section{Independent Variable 2 (asset-holding intention):}

(a) Short-term: The holding company plans to sell the investment stock at an opportune moment in the following year, which means that the available-for-sale financial asset would be categorized as a current asset.

(b) Long-term: The holding company intends to hold onto the stock for the next several years, which means that the available-for-sale financial asset would be categorized as a non-current asset.

\section{Dependent Variable 1: Perception of Relevance (Hypothesis 1)}

Participants measured the relevance of the fair value information of the available-for-sale financial asset.

Dependent Variable 2: Perception of Representational Faithfulness (Hypothesis 2)

Participants measured the representational faithfulness of the fair value information of the available-for-sale financial asset.

\section{Dependent Variable 3: Perception of Decision Usefulness (Hypotheses 3 and 4)}

Participants measured the usefulness of the fair value information in their assessment of investment performance.

All three dependent variables were measured on 11-point scales from 0 to 10 (with 10 indicating the highest degree). They were defined as the difference between this response and the response related to the weather forecast information in making the umbrella decision.

\subsection{Experimental Procedure}

Participants in this study were graduate students from the accounting departments of eight universities in Taiwan. A $2 \times 2$ mixed design was used, including a between-subjects design and a within-subjects design, which resulted in four versions of the questionnaire. The questionnaires were distributed to participants randomly, and each participant filled out only one version. Each questionnaire contained two scenarios, which took an average of 10 to 15 minutes to complete. Following completion, participants were compensated for their time with a payment of NTD 100.

\subsection{Subject Screening and Effective Samples}

A total of 265 questionnaires were distributed, and following the elimination of those with incomplete responses, 257 valid questions remained (response rate of 97\%). Among our participants, $116(45 \%)$ were male, 20 (7\%) had between one and 20 years work experience, and 38 (15\%) had experience in making investments, with an average length of three years. All participants had taken courses associated with accounting and finance; therefore, we assumed that they possessed basic knowledge of the qualitative characteristics of accounting information and the definition of fair value. On the whole, participants felt that the questionnaire was clear and easy to understand (mean response was 5.89 , which is significantly higher than the middle option $5 ; \mathrm{t}=6.84 ; \mathrm{p}=0.01$ ).

\section{Results}

\subsection{Descriptive Statistics}

Table 2 presents the descriptive statistics of the variables used in this study. Panel A presents the assessment results for relevance $(\mathrm{R})$, with a t-test revealing that the high relevance treatment perceived a significantly higher degree of relevance than the low relevance group (means 0.12 and -0.93 , respectively; $t=3.22 ; \mathrm{p}=0.01$ ). Panel $\mathrm{B}$ shows that the group that reported high representational faithfulness $(\mathrm{RF})$ perceived a significantly higher degree of representational faithfulness than the low representational faithfulness group (means 0.63 and -0.11 , respectively; $t=2.30 ; p=0.02$ ). 
These results demonstrate the effectiveness of the information manipulation applied in this experiment.

Table 2. Descriptive statistics

\begin{tabular}{|c|c|c|c|c|c|c|}
\hline \multicolumn{2}{|c|}{ Group } & $\begin{array}{l}\text { Number of } \\
\text { participants }\end{array}$ & Individual mean & $\begin{array}{c}\text { Group } \\
\text { mean }\end{array}$ & t-value & P-value \\
\hline \multicolumn{7}{|c|}{ Panel A: Relevance (R) assessment } \\
\hline \multirow{2}{*}{ High R group } & High R low RF & $\mathrm{N}=63$ & $-0.13(2.61)$ & 0.12 & \multirow[t]{4}{*}{3.22} & \multirow[t]{4}{*}{0.01} \\
\hline & High R high RF & $\mathrm{N}=58$ & $0.40(2.47)$ & \multirow{3}{*}{-0.93} & & \\
\hline \multirow{2}{*}{ Low R group } & Low R high RF & $\mathrm{N}=65$ & $-0.57(2.70)$ & & & \\
\hline & Low R low RF & $\mathrm{N}=71$ & $-1.27(2.65)$ & & & \\
\hline \multicolumn{7}{|c|}{ Panel B: Representational faithfulness (RF) assessment } \\
\hline \multirow{2}{*}{ High RF group } & High R high RF & $\mathrm{N}=58$ & $0.91(2.34)$ & \multirow[t]{2}{*}{0.63} & \multirow[t]{4}{*}{2.30} & \multirow[t]{4}{*}{0.02} \\
\hline & Low R high RF & $\mathrm{N}=65$ & $0.37(2.30)$ & & & \\
\hline \multirow{2}{*}{ Low RF group } & High R low RF & $\mathrm{N}=63$ & $-0.22(2.53)$ & \multirow[t]{2}{*}{-0.11} & & \\
\hline & Low R low RF & $\mathrm{N}=71$ & $-0.01(2.96)$ & & & \\
\hline \multicolumn{7}{|c|}{ Panel C: Decision usefulness assessment } \\
\hline High R low RF & & $\mathrm{N}=63$ & $0.27(2.65)$ & \multirow[t]{2}{*}{ NA } & NA & \multirow[t]{4}{*}{ NA } \\
\hline High R high RF & & $\mathrm{N}=58$ & $0.36(2.68)$ & & & \\
\hline Low R high RF & & $\mathrm{N}=65$ & $-0.88(2.02)$ & \multirow[t]{2}{*}{ NA } & & \\
\hline Low R low RF & & $\mathrm{N}=71$ & $-1.13(2.85)$ & & & \\
\hline
\end{tabular}

Note 1: Participants who obtained fair value information from an active securities market were designated the high representational faithfulness group, whereas participants that obtained fair value information come from observable inputs calculated by using an investment model were designated as the low representational faithfulness group. Furthermore, participants that were given fair value information associated with an available-for-sale financial asset to be sold in the following year were categorized as the high relevance group, while participants that were given fair value information associated with an available-for-sale financial asset to be held far in the future were categorized as the low relevance group.

Note 2: The qualitative characteristics of the information were measured on a scale from 0 to 10 , with a higher score indicating that the participant perceived the qualitative characteristic more strongly.

Table 3 presents the correlation among the qualitative characteristics and decision usefulness of the information. The right upper half presents the Pearson correlation matrix and the left lower half is the Spearman correlation matrix. The results in the table show a significantly positive correlation among the characteristics, as predicted.

Table 3. Correlation analysis of the qualitative characteristics and usefulness of accounting information in making decisions

\begin{tabular}{lccc}
\hline & Relevance & $\begin{array}{c}\text { Representational } \\
\text { faithfulness }\end{array}$ & $\begin{array}{c}\text { Usefulness in making } \\
\text { decisions }\end{array}$ \\
\hline Relevance & 1 & $0.268^{* *}$ & $0.570^{* *}$ \\
\hline Representational faithfulness & $0.185^{* *}$ & 1 & $0.442^{* *}$ \\
\hline Usefulness in making decisions & $0.528^{* *}$ & $0.381^{* *}$ & 1 \\
\hline
\end{tabular}

4.2 Hypothesis Testing

4.2.1 Results of the Experiment with the Mixed Design

For the $2 \times 2$ mixed design adopted for our experiment, we used repeated ANOVA to test Hypotheses 1 and 2 . Table 4 presents the empirical results. Panel A presents our analysis results from the within-subjects design for asset-holding intention and a between-subjects design for the method used to appraise fair value. The testing of the within-subjects effect in Panel A-1 indicates that the asset-holding intention of the holding corporation (degree of relevance) had a significant influence on perceived relevance $(\mathrm{p}<0.01)$. Furthermore, the t-test showed that the relevance of fair value information related to financial assets held for the short-term was higher than that related to financial assets held for the long-term (means -0.02 and -0.28 , respectively; $\mathrm{t}=5.52 ; \mathrm{p}=0.01$ ). Thus, $\mathrm{H} 1$ is supported. The testing of the between-subjects effect in Panel A-2 indicates that the method used in the appraisal of fair value did not influence the perceptions of representational faithfulness $(\mathrm{p}=0.08)$. The t-test revealed that determining the fair value of the financial assets using directly observable markets enhanced representational faithfulness in the minds of decision makers compared with using model appraisal (means 0.76 and 0.04 , respectively; $\mathrm{t}=2.28 ; \mathrm{p}=0.02$ ). Thus, H2 is supported. Moreover, the results obtained from this group show that the usefulness of this information, as perceived by decision makers, was influenced only by asset-holding intention $(\mathrm{p}<0.01)$. 
Panel B of Table 4 presents the analysis results from the within-subjects design adopted for the method used to appraise fair value and the between-subjects design used for asset-holding intention. The testing of the within-subjects effect in Panel B-1 indicates that the method used to appraise fair value (degree of representational faithfulness) had a significant influence on the degree to which participants perceived representational faithfulness $(p<0.001)$. Furthermore, the $t$-test revealed that decision makers perceived greater representational faithfulness when a fair value was determined using directly observable markets compared with the use of model appraisal (means 0.67 and -0.68 , respectively; $\mathrm{t}=6.02 ; \mathrm{p}<0.01$ ). This result supports $\mathrm{H} 2$. The testing of the between-subjects effects in Panel B-2 revealed that the asset-holding intentions of owners (degree of relevance) had a significant influence on the degree to which decision makers viewed the information as relevant $(\mathrm{p}=0.002)$. The $\mathrm{t}$-test indicated that the fair value information related to financial assets held for the short-term was of higher relevance than that related to financial assets held over the long-term (means 0.13 and -1.10 , respectively; $t=5.20 ; p<0.01$ ), which supports $\mathrm{H} 1$. We also determined that the method by which fair value was appraised significantly influenced the degree to which decision makers viewed the information as relevant $(\mathrm{p}<0.001)$ and useful in guiding decisions $(\mathrm{p}<0.001)$. Furthermore, the intention of the firm in holding onto assets was shown to have a significant influence on the degree to which decision makers perceived information as useful in making decisions $(\mathrm{p}=0.009)$ as well as the degree to which it was perceived as relevant.

A comparison of the results in Panels A and B of Table 4 shows that the intention to hold assets had a significant influence on the degree to which decision makers perceived information as relevant (H1), regardless of which experimental design was adopted. Moreover, the method used in the appraisal of fair value was shown to have a significant influence on the degree to which decision makers perceived information as being representational faithful (H2). This means that participants were extremely sensitive to these two variables, such that the testing of $\mathrm{H} 1$ and $\mathrm{H} 2$ produced consistent results.

\subsubsection{Experimental Results Using Only the Between-Subjects Design}

To further verify the test results for $\mathrm{H} 1$ and $\mathrm{H} 2$, we selected only the data from Scenario 1 (between-subjects design for both asset-holding intention and the method used in the appraisal of fair value) in the four questionnaire versions used to perform a $2 \times 2$ two-way ANOVA. The results show a clear connection between asset-holding intention and the degree of perceived relevance $(\mathrm{p}=0.001)$. The $\mathrm{t}$-test also showed that the relevance of fair value information with short-term asset-holding intention was perceived to be higher than that of fair value information with long-term asset-holding intention (means 0.124 and -0.934 , respectively; $\mathrm{t}=3.22 ; \mathrm{p}=0.01$ ). Thus, $\mathrm{H} 1$ is supported. The method used in the appraisal of fair value also had a significant influence on the degree of perceived relevance, which means that the degree of perceived relevance in fair value information based on an active market was higher than that in information based on model appraisal (means -0.114 and -0.731 , respectively; $\mathrm{t}=1.86 ; \mathrm{p}=0.064$ ).

The result illustrates the significant relationship between the method used in the appraisal of fair value and the degree of perceived representational faithfulness $(\mathrm{F}=5.59, \mathrm{p}=0.019)$. This finding shows that the participant's belief in representational faithfulness varied with the method used to appraise fair value. In addition, the t-test showed that fair value information based on an active market was perceived to have greater representational faithfulness than was information derived from a model (means 0.626 and -0.112 , respectively; $\mathrm{t}=2.30 ; \mathrm{p}=0.02$ ). As a result, $\mathrm{H} 2$ is supported. Furthermore, the result indicates that asset-holding intention did not influence the participant's perceived representational faithfulness $(\mathrm{F}=0.27, \mathrm{p}=0.60)$. In conjunction with the fact that the representational faithfulness of fair value information influences the perceived degree of relevance $(\mathrm{F}=3.48, \mathrm{p}=0.06)$, it is likely that a unidirectional relationship exists between relevance and representational faithfulness. Thus, we also performed path analysis to examine the relationship between them.

Further, the result also shows a clear connection between asset-holding intention and the degree to which participants perceived information as useful in guiding decisions $(\mathrm{p}<0.001)$. The $\mathrm{t}$-test revealed that participants perceived the usefulness of fair value information with short-term asset-holding intention as higher than that of fair value information with long-term asset-holding intention (means 0.314 and -1.007 , respectively; $\mathrm{t}=3.98 ; \mathrm{p}<0.00$ ).

\subsubsection{Additional Analysis}

To verify the robustness of the empirical results, we performed additional analysis on the results to exclude individual standards related to the qualitative characteristics of the information. In other words, we used the assessments of relevance, representational faithfulness, and decision usefulness in the accounting decision case as dependent variables to test $\mathrm{H} 1$ and $\mathrm{H} 2$.

Our results show that using a within-subjects design for the appraisal of fair value and a between-subjects design for 
the identification of asset-holding intention produces similar results, regardless of whether the umbrella decision results are taken into account. One exception to this is the situation in which asset-holding intention and the degree of perceived relevance are not significantly correlated when the umbrella decision is not taken into account $(\mathrm{F}=2.26$, $\mathrm{p}=0.13$ ). In other words, the difference between the umbrella decision results and accounting results serve as dependent variables, whereas the accounting results serve directly as dependent variables when the umbrella decision results are excluded. Moreover, all the results of using a within-subjects design for the identification of asset-holding intention and a between-subjects design for the appraisal of fair value are the same as the umbrella decision results.

Using only the between-subjects data, the method used in the appraisal of fair value was found to be significantly correlated with relevance and representational faithfulness $(\mathrm{F}=8.25, \mathrm{p}=0.005 ; \mathrm{F}=7.73, \mathrm{p}=0.01)$; however, asset-holding intention was significantly correlated only with relevance $(\mathrm{F}=7.98, \mathrm{p}=0.005)$. Thus, the main results are similar to those based on the umbrella decision control. To summarize, the results obtained when only the accounting decision is considered are similar to those obtained when the umbrella decision is also included.

Table 4. Results of the experiment with a mixed design

\begin{tabular}{|c|c|c|c|c|c|c|c|c|c|c|c|c|}
\hline \multirow[b]{2}{*}{ Source } & \multicolumn{5}{|c|}{ Assessment of relevance } & \multicolumn{3}{|c|}{$\begin{array}{c}\text { Assessment of representational } \\
\text { faithfulness }\end{array}$} & \multicolumn{4}{|c|}{$\begin{array}{l}\text { Assessment of usefulness in guiding } \\
\text { decisions }\end{array}$} \\
\hline & df & $\begin{array}{l}\text { Mean } \\
\text { square }\end{array}$ & $\begin{array}{c}\mathrm{F}- \\
\text { statistic }\end{array}$ & P-value & df & $\begin{array}{l}\text { Mean } \\
\text { square }\end{array}$ & $\begin{array}{c}\mathrm{F}- \\
\text { statistic }\end{array}$ & P-value & df & $\begin{array}{l}\text { Mean } \\
\text { square }\end{array}$ & $\begin{array}{c}\mathrm{F}- \\
\text { statistic }\end{array}$ & P-value \\
\hline \multicolumn{13}{|c|}{ Panel A: Within-subjects design for asset-holding intention and between-subjects design for the method used in the appraisal of fair value ( $\mathrm{n}=129$ ) } \\
\hline \multicolumn{13}{|c|}{ Panel A-1: Within-subjects effect } \\
\hline Asset-holding intention & 1 & 103.05 & 30.96 & $<0.001$ & 1 & 1.36 & 0.84 & 0.36 & 1 & 90.79 & 31.16 & $<0.001$ \\
\hline $\begin{array}{l}\text { Asset-holding intention } \times \text { Method } \\
\text { used in the appraisal of fair value }\end{array}$ & 1 & 3.56 & 1.07 & 0.303 & 1 & 1.36 & 0.84 & 0.36 & 1 & 3.47 & 1.19 & 0.277 \\
\hline Error & 127 & 3.33 & & & 127 & 1.61 & & & 127 & 2.913 & & \\
\hline \multicolumn{13}{|l|}{ Panel A-2: Between-subjects effect } \\
\hline Intercept & 1 & 109.66 & 8.51 & 0.004 & 1 & 41.51 & 3.77 & 0.054 & 1 & 36.43 & 3.19 & 0.077 \\
\hline $\begin{array}{l}\text { Method used in the appraisal of fair } \\
\text { value }\end{array}$ & 1 & 0.28 & 0.02 & 0.883 & 1 & 32.76 & 2.97 & 0.087 & 1 & 23.40 & 2.05 & 0.155 \\
\hline Error & 127 & 12.88 & & & 127 & 11.004 & & & 127 & 11.428 & & \\
\hline \multicolumn{13}{|c|}{ Panel B: Within-subjects design for the method used in the appraisal of fair value and between-subjects design for asset-holding intention ( $\mathrm{n}=128$ ) } \\
\hline \multicolumn{13}{|l|}{ Panel B-1: Within-subjects effect } \\
\hline $\begin{array}{l}\text { Method used in the appraisal of fair } \\
\text { value }\end{array}$ & 1 & 45.82 & 20.88 & $<0.001$ & 1 & 117.31 & 36.13 & $<0.001$ & 1 & 44.66 & 13.84 & $<0.001$ \\
\hline $\begin{array}{l}\text { Method used in the appraisal of fair } \\
\text { value } \times \text { Asset-holding intention }\end{array}$ & 1 & 1.19 & 0.54 & 0.463 & 1 & 0.43 & 0.13 & 0.715 & 1 & 0.04 & 0.01 & 0.907 \\
\hline Error & 126 & 2.20 & & & 126 & 3.25 & & & 126 & 3.23 & & \\
\hline \multicolumn{13}{|l|}{ Panel B-2: Between-subjects effect } \\
\hline Intercept & 1 & 27.98 & 2.77 & 0.102 & 1 & 0.00 & 0.00 & 0.998 & 1 & 80.07 & 6.82 & 0.01 \\
\hline Asset-holding intention & 1 & 96.26 & 9.59 & 0.002 & 1 & 0.46 & 0.05 & 0.833 & 1 & 82.50 & 7.02 & 0.009 \\
\hline Error & 126 & 10.03 & & & 126 & 10.52 & & & 126 & 11.74 & & \\
\hline
\end{tabular}

\subsubsection{Structural Equation Modeling (SEM)}

We tested all of our hypotheses using ANOVA as well as SEM. We adopted the degree to which participants perceived relevance, representational faithfulness, and the usefulness of information in making accounting decisions as dependent variables in $\mathrm{SEM}^{1}$, the results of which are presented in Figure 1. The $\mathrm{X}^{2}$ value in SEM was 7.80 $(\mathrm{P}=0.099)$, which means a good fit. The RMSEA and SRMR values were 0.06 and 0.03 , both of which meet the standards for a good absolute fit; $\mathrm{TLI}=0.94$ and $\mathrm{CFI}=0.97$, which also reaches the index standards for reasonable incremental fit.

The results in Figure 1 show that asset-holding intention had a significant influence on the degree to which participants perceived relevance $(0.67, \mathrm{p}=0.002 ; 0.63, \mathrm{p}=0.006)$, while the method used in the appraisal of fair value was shown to have a significantly positive influence on the degree to which participants perceived representational faithfulness $(0.66, \mathrm{p}=0.006 ; 0.86, \mathrm{p}=0.001)$. Thus, $\mathrm{H} 1$ and $\mathrm{H} 2$ are both supported. This finding shows that the method used in the appraisal of fair value largely determines how decision makers perceive representational faithfulness in fair value information. Furthermore, the asset-holding intention of the corporation was also shown to affect the degree of participants' perceived relevance.

Our results on the influence of relevance and representational faithfulness on decision usefulness indicate that the degree to which participants perceived relevance and representational faithfulness have a significantly positive influence on perceptions of decision usefulness $(0.33, p=0.001 ; 0.36, p=0.001)$. Thus, H3A and H3B are supported. This means that assessments of relevance and representational faithfulness influence perceptions of the usefulness of fair value information in making decisions. This is consistent with the findings of Kadous et al. (2012).

The degree to which participants perceived representational faithfulness was shown to influence the degree to which they perceived relevance $(0.31, \mathrm{p}=0.001)$. The degree to which participants perceived relevance was also shown to 
have a significantly positive influence on the degree to which they perceived representational faithfulness $(0.32$, $\mathrm{p}=0.001$ ). This finding indicates that the two qualitative characteristics of accounting information are not mutually exclusive, but rather correlated. As a result, $\mathrm{H} 4 \mathrm{~A}$ and $\mathrm{H} 4 \mathrm{~B}$ are supported. This means that the degree to which participants perceived representational faithfulness (relevance) influences the degree to which they perceived relevance (representational faithfulness), which in turn influences the degree to which participants viewed information as useful in guiding decisions. The conclusions drawn in this study are thus similar to those reported by Kadous et al. (2012). However, we found that the influence between the two variables moves in both directions, contrary to the findings of Kadous et al. (2012).

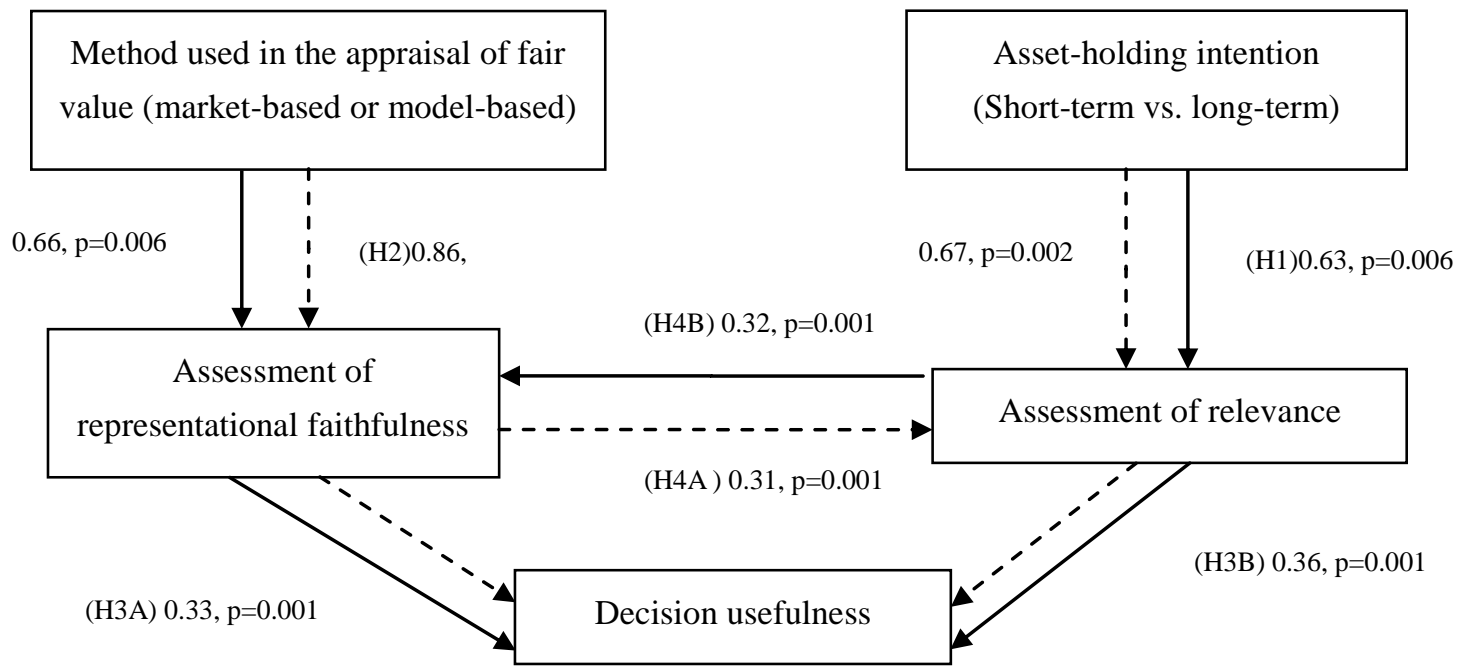

Figure 1. Relationships among the accounting information variables

Note: The bold lines indicate the analysis paths related to the influence of perceived relevance on perceptions of representational faithfulness. The dashed lines indicate analysis paths related to the influence of perceived representational faithfulness on perceptions of relevance.

The combined results of Table 4 and Figure 1 reveal that regardless of the research design or methods used in the statistical analysis, asset-holding intention had a significant influence on the perceptions of relevance, while the method used in the appraisal of fair value was also shown to have a significant influence on perceptions of representational faithfulness. Furthermore, the results in Table 4 indicate that under most circumstances, the method used in the appraisal of fair value significantly affected the degree to which participants perceived representational faithfulness as well as relevance. Moreover, the SEM analysis in Figure 1 shows the degree to which participants perceived that relevance and representational faithfulness influence perceptions of the usefulness of fair value information in making decisions (direct effect) and the degree to which relevance and representational faithfulness influence each other (indirect effect). The results of this study thus indicate that it is difficult for decision makers to consider the relevance and representational faithfulness of information separately in the decision-making process.

\subsection{Other Analysis: Participant Self-Reports}

1. Which is more important, relevance or representational faithfulness?

In the questionnaires, participants were asked to report the importance of the relevance and representational faithfulness of accounting information by using an 11-point scale (from 0 to 10) when using said information to make a decision. The purpose was to provide indirect evidence as to whether relevance or representational faithfulness was more important. According to participants, the mean importance of both relevance and representational faithfulness was 8.15 . In other words, they were rated as equal in importance.

\section{Order of relevance and assessments of representational faithfulness}

We also sought to obtain indirect evidence of whether relevance and representational faithfulness are mutually exclusive by asking participants which they consider first, relevance or representational faithfulness, or whether they consider them both at the same time. Our results revealed that $46.30 \%$ of participants assessed relevance before they assessed representational faithfulness, $27.23 \%$ assessed both at the same time, and $26.45 \%$ assessed representational 
faithfulness before assessing relevance. From this finding, we can infer that the majority of participants (72.75\%) feel that a particular order should be followed to assess relevance and representational faithfulness, which confirms our assertion that these two qualitative characteristics are not mutually exclusive, as implied in the Conceptual Framework.

\section{Conclusion}

The fact that fair value reflects the latest financial performance of a corporation means that expanding its use in financial statements is the logical next step. The IASB has outlined three levels to facilitate the appraisal of fair value under the assumption that the process involved depends largely on subjective judgment (Landsman 2007) as well as the various characteristics associated with relevance or representational faithfulness.

This study aimed to determine the year-end fair value of an available-for-sale financial asset from the perspective of decision makers. We adopted the method used in the appraisal of fair value and asset-holding intention as independent variables to explore whether these variables influence the degree to which decision makers perceive relevance and representational faithfulness in fair value information and whether this affects their perceptions of the usefulness of this information in making decisions. We also investigated the relationship between relevance and representational faithfulness to determine whether they are mutually exclusive, as implied in the Conceptual Framework, whether they have a unidirectional relationship, as posited by Kadous et al. (2012) (with only representational faithfulness influencing relevance), or whether they influence each other. The relationships among the various variables were examined by using ANOVA and SEM.

Our results revealed that under most circumstances, representational faithfulness influences assessments of representational faithfulness, relevance, and decision usefulness, whereas relevance influences only assessments of relevance and decision usefulness. Moreover, assessments of representational faithfulness and relevance are not mutually exclusive but rather significantly correlated. Finally, we established that assessments of representational faithfulness and relevance both significantly influence whether decision makers perceive information as useful in making decisions.

Participants in this study were students without practical experience; therefore, determining whether the results are applicable to astute users of financial statements will require further verification. Actual users of financial statements could thus be recruited for experiments in the future. Second, this study discusses only fair value information related to financial assets. The recognition of fair value appraisal results may vary with the type of asset. For instance, the fair values of available-for-sale financial assets are listed under other comprehensive income items, whereas the fair values of investment properties are listed as profits or losses in the current period. It is therefore unclear whether the findings of this study are applicable to other types of information in financial statements. Furthermore, it is unclear whether the relationships among these variables vary with the financial statement user. This issue will require further comparison and analysis with different types of accounting information and different users in the future.

\section{References}

Barth, M. (1994). Fair value accounting: Evidence from investment securities and the market valuation of banks. The Accounting Review, 69(1), 1-25.

Barth, M. E., Landsman, W. R., \& Wahlen, J. M. (1995). Fair value accounting: Effects on banks' earnings volatility, regulatory capital, and value of contractual cash flows. Journal of Banking \& Finance, 19(3-4), 577-605. http://dx.doi.org/10.1016/0378-4266(94)00141-O

Barth, M. E., Beaver, W. H., \& Landsman, W. R. (1996). Value-relevance of banks' fair value disclosures under SFAS No. 107. Accounting Review, 71(4), 513-537.

Barth, M. E., \& Clinch, G. (1998). Revalued financial, tangible, and intangible assets: Associations with share prices and non-market-based value estimates. Journal of Accounting Research, 36, 199-233. http://dx.doi.org/10.2307/2491314

Barth, M. E., Beaver, W. H., \& Landsman, W. R. (2001). The relevance of the value relevance literature for financial accounting standard setting: Another view. Journal of Accounting and Economics, 31(1-3), 77-104. http://dx.doi.org/10.1016/S0165-4101(01)00019-2

Barth, M. E., Landsman, W. R., \& Lang, M. H. (2008). International accounting standards and accounting quality. Journal of Accounting Research, 46(3), 467-498. http://dx.doi.org/10.1111/j.1475-679X.2008.00287.x

Bricker, R., \& Chandar, N. (2012). Relevance, reliability and restricted security fair values: A look at investment trusts. Managerial Finance, 38(12), 1203-1225. http://dx.doi.org/10.1108/03074351211271292 
Carroll, T. J., Linsmeier, T. J., \& Petroni, K. R. (2003). The reliability of fair value versus historical cost information: Evidence from closed-end mutual funds. Journal of Accounting, Auditing \& Finance, 18(1), 1-24. http://dx.doi.org/10.1177/0148558X0301800101

Cotter, J., \& Richardson, S. (2002). Reliability of asset revaluations: The impact of appraiser independence. Review of Accounting Studies, 7(4), 435-457. http://dx.doi.org/10.1023/A:1020763612369

Duncan, K., \& Moores, K. (1988). Usefulness of CCA information for investor decision making: A laboratory experiment. Accounting and Business Research, 18(70), http://dx.doi.org/10.1080/00014788.1988.9729357

Dye, R. A., \& Sridhar, and S. S. (2004). Reliability-relevance trade-offs and the efficiency of aggregation. Journal of Accounting Research, 42(1), 51-88. http://dx.doi.org/10.1111/j.1475-679X.2004.00129.x

Eccher, E. A., Ramesh, K., \& Thiagarajan, S. R. (1996). Fair value disclosures by bank holding companies. Journal of Accounting and Economics, 22(1-3), 79-117. http://dx.doi.org/10.1016/S0165-4101(96)00438-7

Hague, I., \& Willis, D. (1999). Old price or new? CA Magazine (February), 47-49.

Hitz, J. M. (2007). The decision usefulness of fair value accounting - A theoretical perspective. European Accounting Review, 16(2), 323-362. http://dx.doi.org/10.1080/09638180701390974

Kadous, K., Koonce, L. \& Thayer, J. M. (2012). Do financial statement users judge relevance based on properties of reliability? The Accounting Review, 87(4), 1335-1356. http://dx.doi.org/10.2308/accr-50157

Koonce, L., Nelson, K. K., \& Shakespeare, C. (2011). Judging the relevance of fair value for financial instruments. The Accounting Review, 86(6), 2075-2098. http://dx.doi.org/10.2308/accr-10134

Landsman, W. R. (2007). Is fair value accounting information relevant and reliable? Evidence from capital market research. Accounting and Business Research, 37(Supplement 1), 19-30. http://dx.doi.org/10.1080/00014788.2007.9730081

Maines, L. A., Wahlen, J. M. (2006). The nature of accounting information reliability: Inferences from archival and experimental research. Accounting Horizons, 20(4), 399-425. http://dx.doi.org/10.2308/acch.2006.20.4.399

Muller III, K. A., \& Riedl, E. J. (2002). External monitoring of property appraisal estimates and information asymmetry. Journal of Accounting Research, 40(3), 865-881. http://dx.doi.org/10.1111/1475-679X.00074

Nelson, K. (1996). Fair value accounting for commercial banks: An empirical analysis of SFAS No. 107. The Accounting Review, 71, 161-182.

Penman, S. H. (2007). Financial reporting quality: Is fair value a plus or a minus. Accounting and Business Research, 37(Supplement 1), 33-44. http://dx.doi.org/10.1080/00014788.2007.9730083

Petroni, K., Wahlen, J. M. (1995). Fair values of equity and debt securities and share prices of property-liability insurers. The Journal of Risk and Insurance, 62(4), 719-737. http://dx.doi.org/10.2307/253592

Schipper, K. (2003). Principles-based accounting standards. Accounting Horizons, 17(1): 61-72. http://dx.doi.org/10.2308/acch.2003.17.1.61

Song, C. J., Thomas, W. B., \& Yi, H. (2010). Value relevance of FAS No. 157 fair value hierarchy information and the impact of corporate governance mechanisms. The Accounting Review, 85(4), 1375-1410. http://dx.doi.org/10.2308/accr.2010.85.4.1375

\section{Notes}

Notes 1 . The $\mathrm{X}^{2}$ value of the SEM analysis using the differences between the results of the accounting decision and the umbrella decision as the dependent variables is $12.71(\mathrm{p}=0.013)$, which does not meet the standard for absolute fit. Consequently, we only considered the accounting decision in the SEM analysis. Nevertheless, the results of the SEM analysis using the differences between the results of the accounting decision and the umbrella decision as dependent variables were identical to those when only the accounting decision was considered. The method used in the appraisal of fair value was shown to have a significantly positive influence on the degree to which participants perceived representational faithfulness $(0.73, \mathrm{p}=0.02 ; 0.58, \mathrm{p}=0.05)$. Asset-holding intention was also shown to have a significantly positive influence on the degree to which participants perceived relevance $(1.01, \mathrm{p}<0.01 ; 1.05$, $\mathrm{p}<0.01)$. The degree to which participants perceived representational faithfulness and relevance both exerted a significantly positive influence on the perception of decision usefulness $(0.32, \mathrm{p}<0.01 ; 0.49, \mathrm{p}<0.01)$. The degrees to which participants perceived representational faithfulness and relevance were also shown to influence each other. 